\title{
Integration of Online Social Network and E-Commerce Business through Facebook Pages
}

\author{
Balvinder $^{1}$, Tripat Deep Singh Dua ${ }^{2}$ \\ ${ }^{1}$ IKG Punjab Technical University, Kapurthla, Punjab, India \\ ${ }^{2}$ Guru Nanak Institute of Management and Technology, Ludhiana, Punjab, India \\ 'Email: btanejaus@gmail.com
}

\section{ARTICLE INFORMATION}

DOI: $10.15415 /$ jotitt.2018.62010

Keywords: Online Social Network, Facebook Page, Page Insights, Paid Promo-tion, Organic Traffic

\begin{abstract}
The aim of this paper is to explore Facebook page options through which e-commerce companies can establish relationship with online social networking users. It explores the various options available on Facebook page like audience building, data analysis, paid promotions etc. Techniques for organic and paid promotion discussed to build the page audience. Comprehensive study on data insights provided by Facebook is tabulated. This paper highlights the factors for integration of Online Social Network and e-commerce to help ecommerce companies to focus on building audience and converting them into sale. A step by step implemen-tation starting from page setup, audience building and data analy-sis is presented.
\end{abstract}

\section{Introduction}

Online Social Networking websites like Facebook, Twitter, Instagram etc. have emerged as new tool for the communication and collaboration on the internet. Large number of people on online social network are active for [1] information sharing, personal activities sharing, product reviews, pictures sharing, opinion expression, sentiment expression, advertise their product/ service, news alerts etc. With the availability of billions of users on the Online Social Networking websites and with the sale of US $\$ 4.5$ trillion by e-commerce companies worldwide, integration of OSN and e-commerce is the demand of the time to exploit the combined benefits.
Established in 2004 [2], Facebook is a famous online social networking website with more than 2.3 million active users at the end of 2018 [3]. Facebook allows individuals to create profile on its website. Users can share text, image, videos, upload their profile picture and cover photo, comment on the post(s), share friends post on their wall, chat with their friends, tag their friends, can give like, love, ha-ha, wow, sad or angry reactions on the post [4]. Apart from the basic features, Ivan Di Capua [5] has identified six categories for which Facebook is utilized by users. These are 1) Maintaining relationships 2) Learning about others 3) Recognition 4) Communication 5) Social influence 6) Experience. 
Facebook provides a tool known as Business Page, through which companies can promote their products or services to Facebook users. Companies can create, setup a business page and build page audience by organic and paid promotion. Through Facebook page companies can view analytics of post(s), likes, reactions, comments, sharing of post data etc. which can be utilized for decision making and forecasting. Facebook also provides CTA (Call-To-Action) facility on the business page, which encourages page audience to perform action for conversion as desired by the company.

With the emergence of Web 2.0 and Enterprise 2.0 in parallel, e-commerce companies are looking for these Online Social Network users to advertise their product. Through the inbound marketing techniques companies can target and retarget the specific audience for better results. In the coming sections this article will focus on the integration of Online Social Network with e-commerce using Facebook.

\section{Background of study}

E-commerce is defined as the process of buying, selling, transferring, or exchanging products, services or information via the public internet or private network [6]. Buying and selling of goods or services involve activities like monetary transaction, e-CRM (Customer Relationship Management), e-cash management, delivery system etc. these days people on the Internet can buy any product or service through websites or from specific App on Android or IOS. Few famous e-commerce websites are amazon. in, amazon.com, flipkart.com, snapdeal.com etc. which provide interactive user interface using shopping cart concept to facilitate the users for easy buying.

Online social network is a new way to communicate, collaborate and contribute one's knowledge on the internet via OSN platforms like Facebook, Twitter, LinkedIn, Instagram etc. In the short time span Facebook has witnessed a large number of registered users. People around the world can have $24^{*} 7$ online presences and can share any type of information personal or commercial on their network and reach to the other people. These OSN encourages users to build online mesh of relationships.

Companies are also reaching out to the people to provide awareness about their product or service through online social networking sites like Facebook. This can be achieved by integrating the online social network with e-commerce.

\section{Purpose of study}

The main aim of the study is to identify the steps involved in setup of Business platform on the Online Social Network by e-commerce companies. This study identifies the steps involved in Facebook page creation, setup, audience building, and page analytics provided by the page. The main objective of the study is "Integration of Online Social Network and E-Commerce Business through Facebook Pages".

\section{Integration of online social network and e-commerce business through facebook page}

As per AIDA (Awareness, Interest, Desire, and Action) principle, the first aim while promoting online is to aware people about product or service provided by the company. After creating the Facebook business page first step is to aware page audience by creating various posts on the page with attractive content, images and videos etc. The Page should involve audience to show interest in product or service by reacting on the post. Reactions include likes, reviews, comments or sharing of post in their network. 
Next step is to encourage interested users to show desire in product or service. After analyzing insights from business page, those who have shown some interest and desire, company can make emotional connect with people by posting series of posts about products and services. The ultimate goal of the company's promotional activities is to convert the page audience desire into action, which encourage the users to buy the product, download app, avail paid services etc. Through the Facebook page CTA (Callto-Action) button, The Company can convert users to perform desired actions like buying a product, clicking link or any desired action. To implement the integration of OSN with e-commerce business, step by step procedure is designed and shown in this article.

Fig. 1 shows the full process diagram from Business Page creation to Data insights for integration. It involves 1) Facebook Business page creation and setup 2) Facebook page post 3) business page audience building 4) Facebook advertisement options 5) Reactions on page post 6) Facebook page insights.

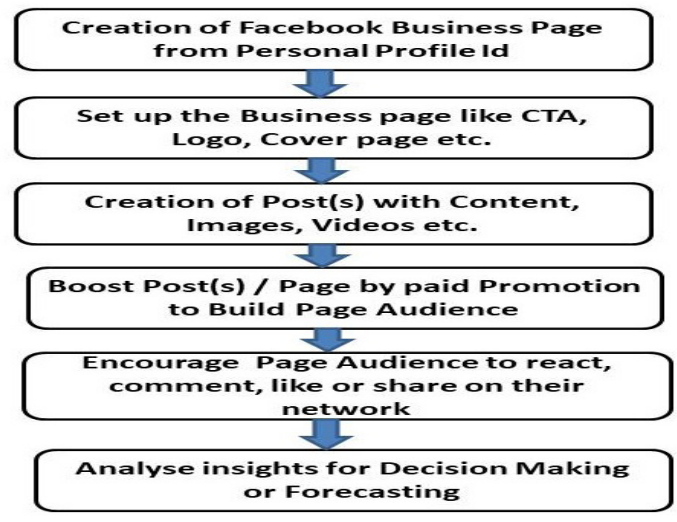

Figure 1: Process diagram from business page creation to data insights

Now we shall discuss these steps one by one with implementation techniques.

\subsection{Facebook business page}

To promote the business on social networks, Facebook provides a tool known as page [7] through these companies can create their own customized page and share their vital information about their products or services. By promoting their product and other information companies can create own brand image, using page companies can target specific audience and communicate with the online users [8]. Facebook allows users to set profile picture like company logo and cover photo which can depict about the company's service through image. To encourage the users to take action when user visits business page, Facebook provides CTA (Call-To-Action) button facility with which company can set one button out of various options available like shop, book, contact, download app, learn more about business or join community.

Facebook page provides publishing tools, insights, setting, hosting events; ads center etc. options to facilitate the companies for a better communication with the page audience. Companies can have page ratings from users or companies can message directly 
to customer. Page audience can also give feedback to companies about their products or services. With so many features provided by Facebook page, it is a very useful tool which can be utilized by e-commerce companies to mark their presence on online social network.

\subsubsection{Facebook page creation}

To create a business page in facebook as shown in Fig. 2, user needs a Facebook profile ID. After logging in into your account, go to create menu and select page option. After selecting Page option, select the category of business page and click create a business page.

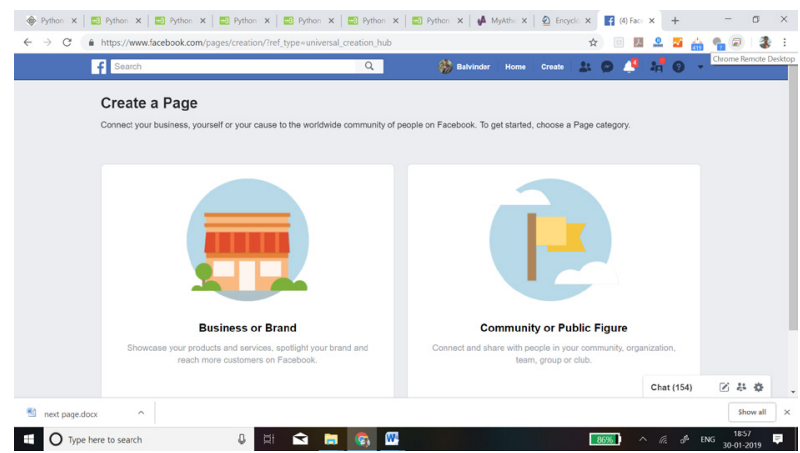

Figure 2: Creation of facebook business page

\subsection{Facebook page post}

To aware the page audience about their product or service companies can post their content via Facebook page post. Facebook provides option to create post(s) where companies can post text content, photos, videos, feeling activity, checking location, write notes, create poll, give list, create watch party, get messages etc. Apart from this, companies can go live, create event, create any offer or create job through post.
Post is a powerful way to reach to page visitors, engage them, encourage them to share post for viral marketing [8] and users can provide review or feedback in comment section. The content provided by the page audience in comment section can be used for the opinion mining [9], which can identify sentiment, feedback about product, emotion or review about the product or service.

Fig. 3 shows the Facebook page of a company with post promoting product with text content and product images.

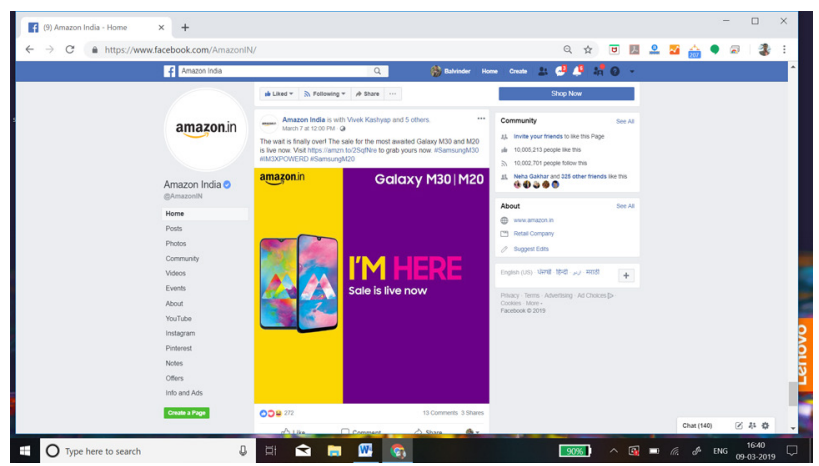

Figure 3: Facebook page post by e-commerce company. 


\subsection{Business page audience building}

After setting up Facebook business page, next step is to build the page audience which may regularly visit page to know about the product or service offered by the company. Facebook users can like [7] any page of their choice in which they have interest and follow the page to get notifications whenever company updates page. To build the audience for Page, Company can promote the page by paid online advertisement [10]. Through the personal profile company can invite Facebook friends to like their page. There are two types of traffic visitors on the business page: Organic traffic 2) Paid traffic.

Organic traffic is number of visitors that visit page without paying or through search result. Paid traffic is the number of visitors that visit on a business page by paying to online social networking websites like Facebook. Cost per click, cost per mile [10] and fixed amount for space on page are the famous paid advertisement option online. Cost per click, is the amount that advertiser pays to OSN site to get click on Ad from a user matching the target audience. Cost per mile is amount paid by the advertiser to OSN for giving one thousand impressions to target audience. By offering these paid ads as sponsored ads company can encourage interested
Facebook users to like their page and become prospectus for future sale. Amazon India, a famous e-commerce company has 10 million likes on their Facebook business page as on Feb 2019. In the similar fashion Snapdeal, MI India, flip kart, Jabong etc. E-commerce platform has millions of followers on the Facebook business page and on other OSN platforms.

\subsection{Facebook ads options}

With the development of internet and advancement in technology, advertisement on the internet has become major activity [11]. Companies develop advertising strategies to target internet based users through search engine, email or online social networks. On the online social networking websites, people with one group or friends have shown similar purchasing behavior [12]. OSN websites like Facebook can target the audience by showing them similar ads as purchased by their group or friends. With the success Facebook, LinkedIn, YouTube like platforms, advertisement on online social networks have received more attention.

Facebook has developed a platform named facebook.com/business, where companies can register and create advertisement. Fig. 4 shows business creation module below:

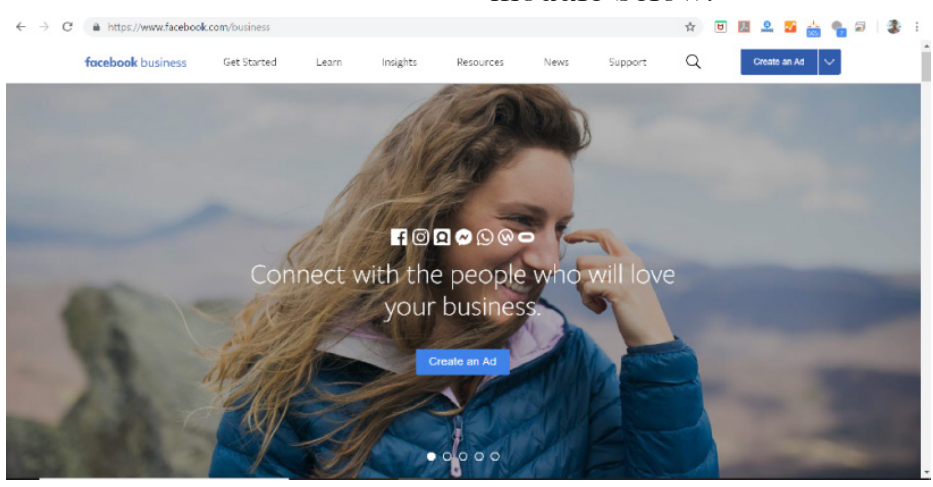

Figure 4: Facebook business advertisement module 
From the business page companies can directly select Boost Post option to promote any post on the page to your customize page audience as shown in Fig. 5. Facebook provides the facility to create targeted audience by age, sex and location. If a company has its own website, by installing
Facebook Pixel Company can target website visitors who have Facebook account to advertise their product or service. The Company can also promote its page, website or business at local level with in few miles through advertisement.

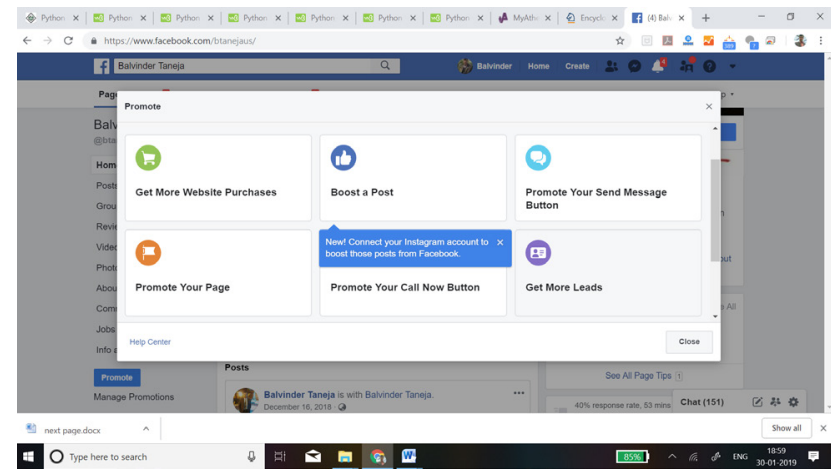

Figure 5: Paid promotion window on facebook page

To run the paid advertisement on Facebook, Instagram or on any other OSN site, companies have to set the goal for running ads campaign. Campaign is an activity performed to run advertisement like post to promote any discount campaign, or any awareness campaign etc. On Facebook there are three types of goal options available.

1. Awareness campaign

2. Consideration campaign

3. Conversion campaign

Awareness campaign can be run to aware about product or services by reaching out to OSN users. Consideration campaign can be run by the companies to encourage the users to consider their products before making any buying decision. Lastly conversion campaign can be run by the companies to encourage customers to take action as required by the companies such as buying product, download app, store visit etc. Facebook runs these advertisements to target customers specifically or broadly as selected by the companies. Fig. 6 shows the types of promotional goals available in Facebook Advertisement module.

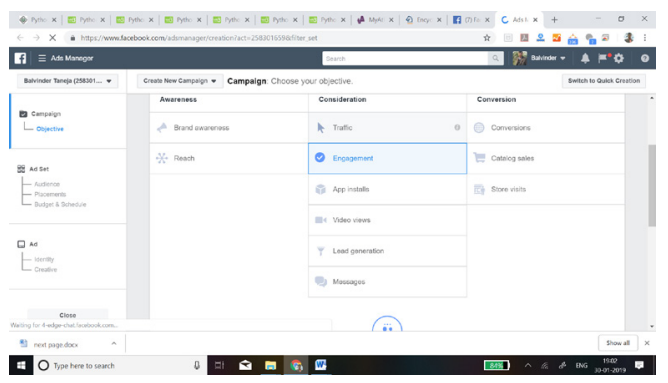

Figure 6: Paid ads goal facebook screen 


\subsection{Reactions on page post}

When companies post on the online social network, passive type of users just see the post, they do not react on the post. But active users always like or react to the post. Users can give their reactions in the form of pressing like button of different variations of love, ha-ha, sad, wow etc. as provided by the OSN website. Users can share any post in their network online, users can give reviews or opinions in the comment section provided by the OSN websites.

Facebook provides various options to provide reactions on the post(s). Users can press like, love, ha-ha, wow, sad etc. to give their reactions. Users can post emoji [13] to provide their sentiments on any post, or user can share. Company's post in his/her network. These types of reactions are known as click speech [14] which provides reactions through simple clicks.

User can also provide his/her opinion in comment section in textual format, which is a more active form of click speech form [15]
[14]. Sentiment through comments can be categorized into positive, negative or neutral polarity [16]. These comments can be analyzed by the companies to get feedback from the users. Different researches are going on this topic which can analyze the unstructured data and generate patterns, that can be utilized by the companies for decision making or forecasting.

By exploring these reactions on Facebook page, e-commerce business companies can establish a virtual relationship [17] with Facebook users. This virtual relationship can contribute in sales improvement, brand building and focus on implement in other areas.

Thus we can say that reactions provided by the users on Facebook brand page depending upon various factors [18] can be utilized by companies for establishing relationships, brand awareness, consideration, sales conversion and forecasting. Fig. 7 shows the example of reactions given by page audiences on a post of a product.

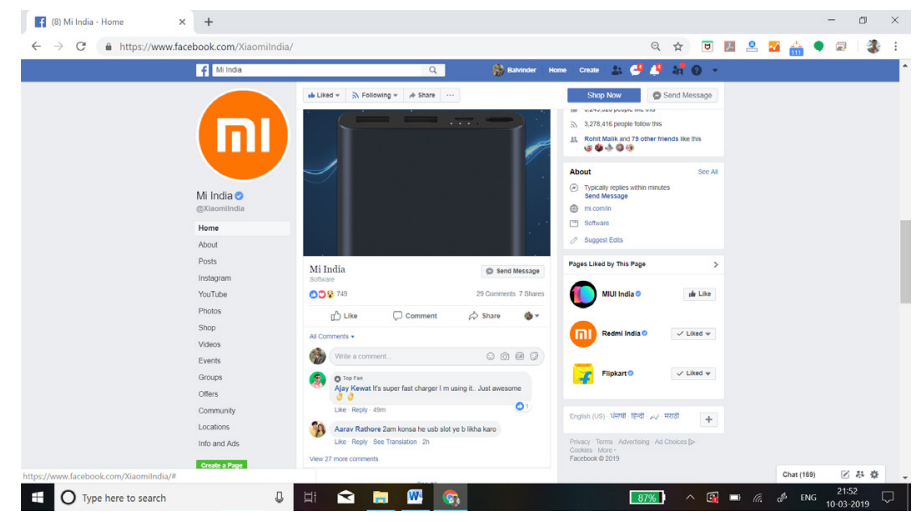

Figure 7: Reactions on company's page post for a product

\section{Facebook page insights}

Beauty of the inbound marketing is that, it provides analytics for campaigns run by the companies. When any company runs promotional campaign on
Facebook page, it provides analytics for campaign through insights tab section available in the business page. It is provided by the URL http://facebook. com/insights. 
Facebook provides insights about how people are engaged with Business Page. It provides various metrics like post clicks, reactions on post, comments on post, no of post shares, number of people reaches, video views etc. it also provides insights for the post(s) which have more number of engagements, people's demographic data, organic and paid reach, page's videos, page's followers, page's views and previews, page's recommendations, and number of page likes.

Companies are interested to view the insights on the following factors [19]

1. Reach: Reach tells about the number of people who had any posts from company's page enter their screen. These are the passive Facebook page users who just see the post.

2. Engagement: It is the customer's behavior [19] towards any brand, firm or page post. Users can click on post, react, comment, shares, view videos etc. are types of engagement. Engagement insight provides data on these above said factors, these are the active Facebook page users who show interest and interact with companies.

3. Conversion: Conversion insights provide data about Call-to-Action. For example number of app downloads number of clicks on link provided, sale conversion, catalogue downloads etc.

As mentioned by the C.S.Christou, et al. [20], Facebook insights tool is used by all the companies as a standard marketing tool as compared to Google Analytics used by 57\%, Hashtag trackers by $43 \%$ and Hootsuite by $29 \%$. So we can say that Facebook insights tool is the most beneficial tool to draw appropriate results.

Now I shall discuss the various Facebook insights options provided by Business page. It is as follows:

Table 1: Various facebook page insights options available through overview tab, followers tab, like tab, reach tab, page views tab, page preview tab, posts tab and people tab

Overview Section: In the overview section
Facebook provides page summary which
includes data about actions on page, page views,
page previews, page likes, post reach, post
engagements, page responsiveness, videos, page
followers, recent promotions by page through
boost posts. In shows data of yesterday, today,
last 7days, last 28 days or as customize by the
company according to dates range.


Like tab: - It shows the total no. of likes, net likes and where your page likes happened.

Reach tab: Post reach tells the number of people who had any posts from company's page enter their screen it shows the post reach and total reach for the page.

Page views tab:- This section shows the data about total people who has viewed your page, and page views by section, by age \& gender, by country and by device

Page preview tab: - This tab shows the total page previews \& page previews by age and gender.

Difference between page views \& page previews is that page views is the no, of times a page's profile has been viewed by $\operatorname{login} \& \log$ out users, whereas page preview is the no. of times people hovers over page picture or page name to see a preview of

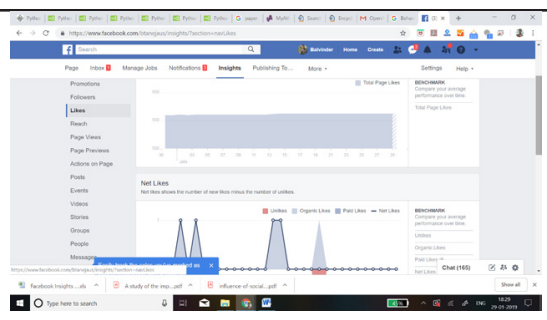

Figure 10: Facebook page like(s) insights page 
Posts tab: - This tab shows data about the posts like all posts published, average reach, average, engagement, top posts from page and timeline which shows the page fans who are online.

People tab: - It shows the data about the people who are page fans, followers and reach to people.

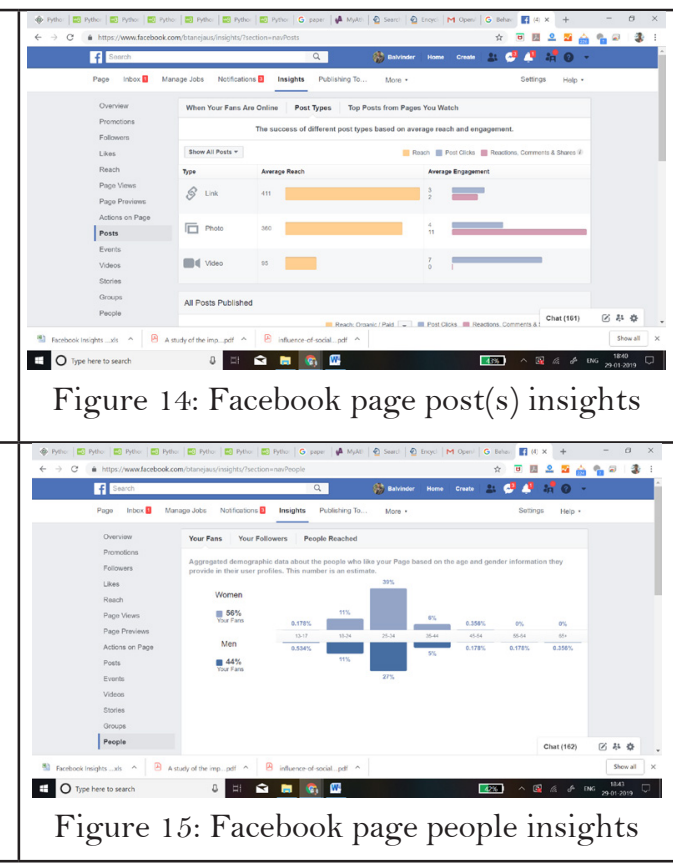

\section{Discussion}

The study explored the different findings, which can be utilized by the companies to show its presence online. Companies can create Business page to mark their presence on Facebook like OSN. To encourage the page audience to perform some action company must put Call to Action button on business page. Post is vital component on the page to build audience, so companies must post content including images, text, audio, videos etc. Data provided by the page audience on posts in the form of reactions must be analyzed by the companies for business generation.

People and followers insights tell about the number of page audience who have liked the page and this number help in deciding about building page audience. Company can go for paid advertisement to attract the online users to like page and become page follower. Reach tab data insights provide data about how posts are reaching on the screen of the users. Reach shows data about how many users are getting aware about the post on the page. It is only through reach company can aware about its product or service. So company can decide to go for paid advertisement to reach more number of people on Online Social Network.

\section{Conclusion}

Integration of OSN and e-commerce can be very beneficial for the e-commerce companies. Companies can exploit the benefits of users by selling them product or service, who spend lot of time on the Social networking websites like Facebook, Instagram, Twitter etc.

This paper mainly discussed about how can a company setup business page, posts content about the products or service, build page audience by organic and paid promotions and setup CTA button for conversion. This paper also discussed the various analytics 
insights option provided by the Facebook business page. Facebook page provides insights in overview section, promotional posts insights section, followers insights section, page like insights section, page reach insights section, page view and page preview insights section, action on the page insights section, posts insight section, people analytics those who are fans of page, and others topics like video analytics section etc.

This type of promotion and branding is future of Marketing. In the coming years more numbers of companies will be on e-commerce platforms, which enhances the scope of integration of OSN and ecommerce. With the currently millions of Facebook pages worldwide, Business can experience exponential growth with OSN and e-commerce platforms in the coming years.

\section{References}

[1] M. Adedoyin-Olowe, M. Gaber and F. Stahl, "A survey of data mining techniques for social network analysis", Lecture Notes in Computer Science, vol. 7895, pp. 135-145, 2014.

[2] C. Lampe and N. Ellison, "Understanding facebook: social computing isn't 'Just' social,' in Computer, vol. 45, no. 9, pp. 98-100, 2012.

[3] United Kingdom. The Statistics Portal, Number of monthly active Facebook users worldwide as of 1st quarter 2019, [Online] Available: https://www.statista.com/statistics/264810/number-of-monthly-active-facebook-users-worldwide/ [Accessed: Feb 10, 2019].

[4] I. R. Chowdhury and B. Saha, "Impact of facebook as a social networking site (sns) on youth generations", a case study of kolkata city". International Journal of Humanities and Social Science Invention, vol. 4, no. 6, pp. 28-42, 2015.
[5] I. D. Capua, "A literature review of research on facebook use", The Open Communication Journal, vol. 6, pp. 37-42, 2012.

[6] E. Turban and L. Volonino, "Information technology for management: improving strategic and operational performance”, Hoboken NJ: John Wiley \& Sons, Inc, 2011.

[7] R. Kaufmann and M. Buckner, "To connect or promote?: An exploratory examination of facebook pages dedicated to moms", Computers in Human Behavior, vol. 35, pp. 479-482, 2014.

[8] C. Castronovo and L. Huang, "Social media in an alternative marketing communication model", Journal of Marketing Development \& Competitiveness, vol. 6, pp. 117-136, 2012.

[9] H. Chen and D. Zimbra, "AI and opinion mining," in IEEE Intelligent Systems, vol. 25, no. 3, pp. 74-80, 2010.

[10] A. A. Galán, J. G. Cabañas, A. Cuevas, M. Calderón and R. C. Rumin, "Largescale analysis of user exposure to online advertising on facebook," IEEE Access, vol.7, pp. 11959-11971, 2019.

[11] Y. Li, B. Q. Zhao, B.R., C. S. L. John, “On modeling product advertisement in largescale online social networks", IEEE/ ACM Transactions on Networking, vol. 20, no. 5, pp. 142-1425 2012.

[12] Z. Sun, S. Firmin, J. Yearwood, "Integrating online social networking with e-commerce based on CBR", in 23rd ACIS 2012 Proceedings, Geelong, pp. 1-11, 2012.

[13] T. Tran, D. Nguyen, A. Nguyen and E. Golen, "Sentiment analysis of marijuana content via facebook emoji-based reactions," 2018 IEEE International Conference on Communications (ICC), Kansas City, MO, pp. 1-6, 2018.

[14] A. Y. K. Chua and S. Banerjee, "Rumor verifications on facebook: click speech 
of likes, comments and shares," 2017 Twelfth International Conference on Digital Information Management (ICDIM), Fukuoka, pp. 257-262, 2017.

[15] A. L. Forest and J. V. Wood, "When social networking is not working: Individual with low self-esteem recognize but do not reap the benefits of self-disclosure on facebook," Psychological Science, vol. 23, no. 3, pp. 295-302, 2012.

[16] J. Martin, A. Ortigosa and R. Carro, "SentBuk: Sentiment analysis for e-learning environments." 2012 Andorra la Vella, Andorra, International Symposium on Computers in Education (SIIE), pp. 1-6, 2012.

[17] D. Tsutsumi and T. Silva, "Identifying virtual relations among businesses exploring user reaction on facebook," 2018 IEEE/WIC/ACM International Conference on Web Intelligence (WI), Santiago, pp. 96-103, 2018.

[18] H. Jeon and H. J. Ahn, "Identification of the factors that affect the user reaction to posts on facebook brand pages," 2015 International Conference on Computer and Computational Sciences (ICCCS), Noida, pp. 203-206, 2015.

[19] L. Mauda and Y. M. Kalman, "Characterizing quantitative measures of user engagement on organizational facebook pages," 2016 49th Hawaii International Conference on System Sciences (HICSS), Koloa, HI, pp. 3526-3535, 2016.

[20] C. S. Christou, D. Ktoridou, A. Papatheocharous and F. Domenach, "Cypriot firms, social media \& usergenerated content platforms," 2015 International Conference on Interactive Mobile Communication Technologies and Learning (IMCL), Thessaloniki, pp. 378382, 2015. 